\title{
Use of PCR-DHPLC with fluorescence detection for the characterization of the bacterial diversity during cassava (Manihot esculenta crantz) fermentation
}

C.S. Kodama ${ }^{1}$, S. Cuadros-Orellana ${ }^{1}$, C.H.M.M. Bandeira ${ }^{2}$, D.A. Graças ${ }^{1}$, A.S. Santos ${ }^{2}$ and A. Silva ${ }^{1}$

${ }^{1}$ Laboratório de Polimorfismo de DNA, Instituto de Ciências Biológicas, Universidade Federal do Pará, Belém, PA, Brasil

${ }^{2}$ Laboratório de Investigação Sistemática em Biotecnologia, Instituto de Ciências Exatas e Naturais, Universidade Federal do Pará, Belém, PA, Brasil

Corresponding author: A. Silva

E-mail: asilva@ufpa.br

Genet. Mol. Res. 13 (1): 1304-1313 (2014)

Received December 19, 2012

Accepted May 17, 2013

Published February 28, 2014

DOI http://dx.doi.org/10.4238/2014.February.28.2

\begin{abstract}
Denaturing high-performance liquid chromatography (DHPLC) has been described as a suitable method to study DNA polymorphisms. Here, cassava (Manihot esculenta Crantz) fermentation liquor was examined using DHPLC analysis to characterize the bacterial diversity during the fermentation process. GC-clamped amplicons corresponding to a variable region of the bacterial community $16 \mathrm{~S}$ rDNA were synthesized using polymerase chain reaction (PCR) and then resolved on a base-composition basis using preparative DHPLC. Eluate fractions were collected at random and used as a source of whole community DNA that could be used to determine the bacterial diversity. As a first approach, GC-clamps were removed from the eluted DNA
\end{abstract}


fragments using PCR to avoid the possible bias these clamps could cause during the construction of clone libraries. As a second approach, a clone library of each eluate sample was constructed, preserving the GC-clamps of the DNA fragments. The first approach generated 132 bacterial rDNA sequences with an average size of $200 \mathrm{bp}, 45 \%$ of which had similarity to unculturable or non-classified bacteria. The second approach produced 194 sequences identified as Proteobacteria (48\%), uncultured or non-classified environmental bacteria (40\%) and Firmicutes (12\%). We detected a remarkably greater bacterial diversity using the first approach than the second approach. The DHPLC-PCR method allowed for the fast and non-laborious detection of a vast bacterial diversity that was associated with cassava fermentation, and we conclude that it is a promising alternative for the characterization of the overall microbial diversity in complex samples.

Key words: Metagenomics; Fermentation; Bacterial diversity; Denaturing high-performance liquid chromatography (DHPLC)

\section{INTRODUCTION}

Denaturing high-performance liquid chromatography (DHPLC) has been pointed out as a rapid, reliable, and highly sensitive method for screening microbial rDNA amplicons for clinical (Hurtle et al., 2003) and industrial (Hutzler et al., 2010) applications. DHPLC has also been used as an accessory method in the clinical diagnosis of human diseases such as Von Willebrand syndrome (Kakela et al., 2006) and cancer (Li et al., 2008).

In the microbial ecology field, DHPLC was recently proven to be a useful method. It has been used, for instance, in the study of marine bacterial diversity (Barlaan et al., 2005), in the analysis of the human gut microbiome during antibiotic theraphy (Goldenberg et al., 2007), in the monitoring of bacterial populations during the treatment of urogenital infections (Domann et al., 2003), and in the determination of endodontic infection-related microbiota (Jacinto et al., 2007).

Endophytic microorganisms are important in agriculture and are regarded to be ubiquitous, i.e., they are found in virtually all cultivable plants including soy (Hung et al., 2007; Li et al., 2008), beans (Trujillo-López et al., 2006), corn (Rijavec et al., 2007), cassava (Teixeira et al., 2007), potato (Rasche et al., 2009), rice (Mattos et al., 2008), and peanut (Ibáñez et al., 2009). Cassava (Manihot esculenta Crantz) storage roots have been widely used for human and animal nutrition, mainly in tropical regions. Industrial processing of cassava results in a number of products such as distilled beverages and biofuels (Choi et al., 2010; Zhang et al., 2010). Like other agronomic crops, cassava may be colonized by different soil microorganisms, such as mycorrhizal fungi and diazotrophic bacteria (Balota et al., 1999; Teixeira et al., 2007).

Because biotechnological processes that are mediated by microorganisms are of industrial interest, the development of alternative methods to study the microbial community composition and dynamics is of prime importance. 


\section{MATERIAL AND METHODS}

\section{Collection and preparation of samples}

Cassava (M. esculenta Crantz) roots were obtained from a local farmer in Belém, PA, Brazil, and they were treated as follows: initial wash with tap water and neutral detergent; immersion in $70 \%$ ethanol for $1 \mathrm{~min}$, in $2 \%$ hypochlorite for $6 \mathrm{~min}$, in $70 \%$ ethanol for $30 \mathrm{~s}$, and a final wash with sterile distilled water. A $50-\mu \mathrm{L}$ aliquot of the final washing water was spread onto potato dextrose agar medium and incubated at $37^{\circ} \mathrm{C}$ for up to 7 days to confirm the superficial sterility of the cassava roots.

Following asepsis, the roots were kept immersed in distilled water $(1: 2, \mathrm{w} / \mathrm{v})$ for 7 days at room temperature. Every $12 \mathrm{~h}, \mathrm{a} 100-\mathrm{mL}$ aliquot of the fermented broth was taken and filtered under a vacuum through sterile $0.22-\mu \mathrm{m}$ nitrocellulose membranes (Whatman, USA). At the end of filtration, the membranes were frozen in buffer containing $1 \mathrm{M} \mathrm{NaCl}, 1 \mathrm{M}$ Tris$\mathrm{HCl}$, and $100 \mathrm{mM}$ EDTA for DNA preservation.

\section{DNA extraction}

The biomass collected on the membranes was used as a source of metagenomic DNA. The Ultra Clean ${ }^{\mathrm{TM}}$ Soil DNA kit (MoBio Laboratories, Inc., USA) was used. The membranes were cut into small pieces and submitted to the bead-beating step for $10 \mathrm{~min}$ with $1.0 \mathrm{~mL}$ bead suspension buffer and $60 \mu \mathrm{L}$ buffer S1. From that step on, the manufacturer instructions were followed.

\section{PCR conditions}

A fragment of approximately $1.5 \mathrm{~kb}$ of the $16 \mathrm{~S}$ rRNA gene was amplified using primers 8F (5'-AGAGTTTGAATYMTGGCTCAG-3') and 1407R (5'-GACGGGCGGTGT GTACAAG-3') (Domann et al., 2003). The PCR $(50 \mu \mathrm{L})$ mixture comprised the following: 5 pmol of each primer, $1.25 \mathrm{mM}$ of each deoxyribonucleotide triphosphate, $1.5 \mathrm{mM}$ magnesium chloride, 1.0 U Taq DNA polymerase (Invitrogen, Brazil), and 50 ng template DNA. Reaction conditions were as follows: 1 cycle of denaturation at $95^{\circ} \mathrm{C}$ for $6 \mathrm{~min} ; 30$ cycles of denaturation at $95^{\circ} \mathrm{C}$ for $1 \mathrm{~min}$, annealing at $60^{\circ} \mathrm{C}$ for $1 \mathrm{~min}$, and elongation at $72^{\circ} \mathrm{C}$ for $1 \mathrm{~min}$; and a final elongation cycle at $72^{\circ} \mathrm{C}$ for $5 \mathrm{~min}$.

An aliquot of this amplicon was used as the template in a second PCR in which a fragment covering the variable region V3 of the $16 \mathrm{~S}$ rDNA was amplified. GC-clamps of 40 bp were added to PCR primers to introduce a high melting temperature domain to each of the target molecules, which was shown by Wurzburger et al. (2003) to help resolve similar fragments on a denaturing gradient electrophoresis gel. PCR optimization was done by testing a GC-clamped set of forward primers that was described by Barlaan et al. (2005), namely FP1, FP2, FP3, FP4, FP5, and FP6, combined with the 534R universal primer, in the amplification of 2 distinct samples that were collected on the first day at 12 and $24 \mathrm{~h}$. Once we determined the best primer combination, it was used to amplify the 16S rDNA from all other metagenomic DNA samples throughout the experiment.

PCR was performed on a MasterCycler thermocycler (Eppendorf, Germany) in 1X 
buffer $(200 \mathrm{mM}$ Tris- $\mathrm{HCl}, \mathrm{pH} 8.0$ and $500 \mathrm{mM} \mathrm{KCl})$. The reaction mixture $(60 \mu \mathrm{L})$ contained the following: $5 \mathrm{pmol}$ of each primer, $1.25 \mathrm{mM}$ of each deoxyribonucleotide triphosphate, 1.5 $\mathrm{mM}$ magnesium chloride, 1.0 U Taq DNA polymerase (Invitrogen), and 50 ng template DNA. PCR conditions consisted of 1 cycle of denaturation at $95^{\circ} \mathrm{C}$ for $5 \mathrm{~min} ; 25$ cycles of denaturation at $95^{\circ} \mathrm{C}$ for $30 \mathrm{~s}$, annealing at $55^{\circ} \mathrm{C}$ for $40 \mathrm{~s}$, and elongation at $72^{\circ} \mathrm{C}$ for $1 \mathrm{~min}$; and a final elongation cycle at $72^{\circ} \mathrm{C}$ for $15 \mathrm{~min}$.

\section{DHPLC separation conditions}

The separation of amplicons was performed in a Transgenomic WAVE 4500 system controlled by a Navigator Software version 2.0.0 and equipped with DNASep cartridges with alkylated non-porous polystyrene-divinylbenzene copolymer microspheres, WAVE HSD (HighSensitivity Detection Module), and Fragment Collector FCW-200 (Transgenomic, USA).

Fragments were resolved on a WAVE system at a constant flow of $0.9 \mathrm{~mL} / \mathrm{min}$. The best column temperature was determined through a screening in which we tested temperatures ranging from $55^{\circ}$ to $74^{\circ} \mathrm{C}$ on a $0.5^{\circ} \mathrm{C}$-step basis. The reverse phase loading mixture was as follows: $65 \%$ buffer A [0.1 M triethylamine/acetate (TEAA), $\mathrm{pH} 7.0]$ mixed with $35 \%$ buffer $\mathrm{B}(25 \%$ acetronitrile in $0.1 \mathrm{M}$ TEAA, $\mathrm{v} / \mathrm{v}, \mathrm{pH} 7.0)$. A gradient was performed starting with a mixture of $60.0 \%$ buffer A and $40.0 \%$ buffer B. At the end point $(17 \mathrm{~min})$, the mixture was $28.0 \%$ buffer A and $72.0 \%$ buffer B. Sequences were detected with a fluorescence detector HSX-3500, and chromatogram analyses were performed with the Navigator ${ }^{\mathrm{TM}}$ software, version 2.0.0 (Transgenomic).

\section{Peak collection strategy}

An aliquot of rDNA amplicons collected from the WAVE system was analyzed using 2 different approaches. The first approach consisted of re-amplifying the sequences to remove the GC-clamps prior to cloning and sequencing; this was accomplished through the use of primers FP1 (Barlaan et al., 2005) (no clamp) and 534R (Muyzer et al., 1993) in a PCR (50 $\mu \mathrm{L}$ ) composed of $5 \mathrm{pmol}$ of each primer, $1.25 \mathrm{mM}$ deoxyribonucleotide triphosphate, $1.5 \mathrm{mM}$ magnesium chloride, 1.0 U Taq DNA polymerase (Invitrogen), and $50 \mathrm{ng}$ template DNA. PCR conditions consisted of 1 cycle of denaturation at $95^{\circ} \mathrm{C}$ for $5 \mathrm{~min} ; 25$ cycles of denaturation at $95^{\circ} \mathrm{C}$ for $30 \mathrm{~s}$, annealing at $55^{\circ} \mathrm{C}$ for $40 \mathrm{~s}$, and elongation at $72^{\circ} \mathrm{C}$ for $1 \mathrm{~min}$; and a final elongation cycle at $72^{\circ} \mathrm{C}$ for $15 \mathrm{~min}$.

In the second approach, DHPLC fractions were directly cloned and sequenced. This was done in order to verify the existence of bias caused by a second PCR, which could lead to a bias in the operational taxonomic unit determination, thus affecting the accuracy of the microbial diversity estimation.

\section{Cloning and sequencing}

DHPLC samples and PCR products without the GC-clamp were ligated into the pGEM ${ }^{\circledR}$-T Easy Vector (Promega Corp., USA) according to the manufacturer instructions, and used to transform electrocompetent DH5a Escherichia coli cells (Stratagene, USA) through a Cell-Porator $E$. coli Electroporation System (Life Technologies, GIBCO BRL, USA). Transformant cells were 
plated onto semi-solid LB agar (DIFCO) that was amended with $100 \mathrm{mg} / \mathrm{mL}$ ampicilin (sodium salt, EMS, Brazil) and $40 \mathrm{mg} / \mathrm{mL}$ X-gal (GE HealthCare, USA). Recombinant clones were detected by the blue/white screening system. Recombinant plasmids were isolated using alkaline lysis miniprep and purified with MAGV N22 membranes (Millipore, USA).

The selected clones were sequenced with the Dye Terminator Cycle Sequencing Kit for MegaBACE using M13 forward and reverse primers (Invitrogen). The samples were read in an automatic DNA sequencer (MegaBACE 1000 DNA Analysis Systems, GE Healthcare).

\section{Data analysis}

Ribosomal RNA gene sequences were analyzed using BioEdit 7.0.5.3 (Hall, 1999) and ClustalW Multiple Alignment Tool (Edgar and Batzoglou, 2006). The identification of microorganisms was performed using the online tool ARB-Silva (Pruesse et al., 2007). Partial 16S rRNA sequences have been deposited in the GenBank database under accession Nos. GU480124 to GU480449.

\section{RESULTS}

The combination of primers FP3 and universal primer 534R for the amplification of the variable region (V3) of the $16 \mathrm{~S}$ rRNA gene was considered to be the best suited for our goals because it generated the most defined and diverse peaks with good resolution, as seen on DHPLC. Thus, this primer pair was chosen for subsequent bacterial diversity analysis. The PCR using FP3/534R yielded amplicons with an average size of $194 \mathrm{bp}$. According to Barlaan et al. (2005), amplification of the V3 region is suitable for the analysis of microbial communities using DHPLC.

The DHPLC separation conditions were optimized, and a constant column temperature of $64.5^{\circ} \mathrm{C}$ worked the best for our samples, resulting in the partial denaturation of DNA and sharp peaks. Similar to Wagner et al. (2009), we did not obtain baseline separated peaks, but this was already expected considering the complexity of our samples.

Twelve peaks corresponding to $16 \mathrm{~S}$ rDNA (Figure 1) were collected at random. Two aliquots of each peak to be sampled were collected. For each peak, 1 aliquot was cloned straight away and the other aliquot was re-amplified with regular (non-clamped) primers to remove the GC-clamp prior to cloning.

As previously mentioned, as a first approach, we prepared a clone library of each of the peak aliquots that had been submitted to a second PCR to remove the GC-clamp. Around 10 clones were selected from each library for sequencing, excepting peak $\mathrm{X}$, from which 30 clones were sequenced because of the apparent higher diversity of the bacterial population. Thus, 140 clones were selected, and 132 of them were successfully sequenced.

As a second approach, we prepared clone libraries of each peak using sequences that still contained the GC-clamp. A total of 194 clones were successfully sequenced.

The microbial diversity, as assessed through DHPLC using the 2 above-mentioned approaches, is presented in Tables $\mathbf{S 1}$ and $\underline{\mathbf{S 2}}$, which are available in the Supplementary material.

Even though some hits that were identified in the first approach corresponded to the same species as those that were identified in the second approach, their accession number was different in some cases, suggesting that there are base-sequence differences between them. 
Exclusive species were detected in each library, which is possibly a consequence of the different approaches that were used.

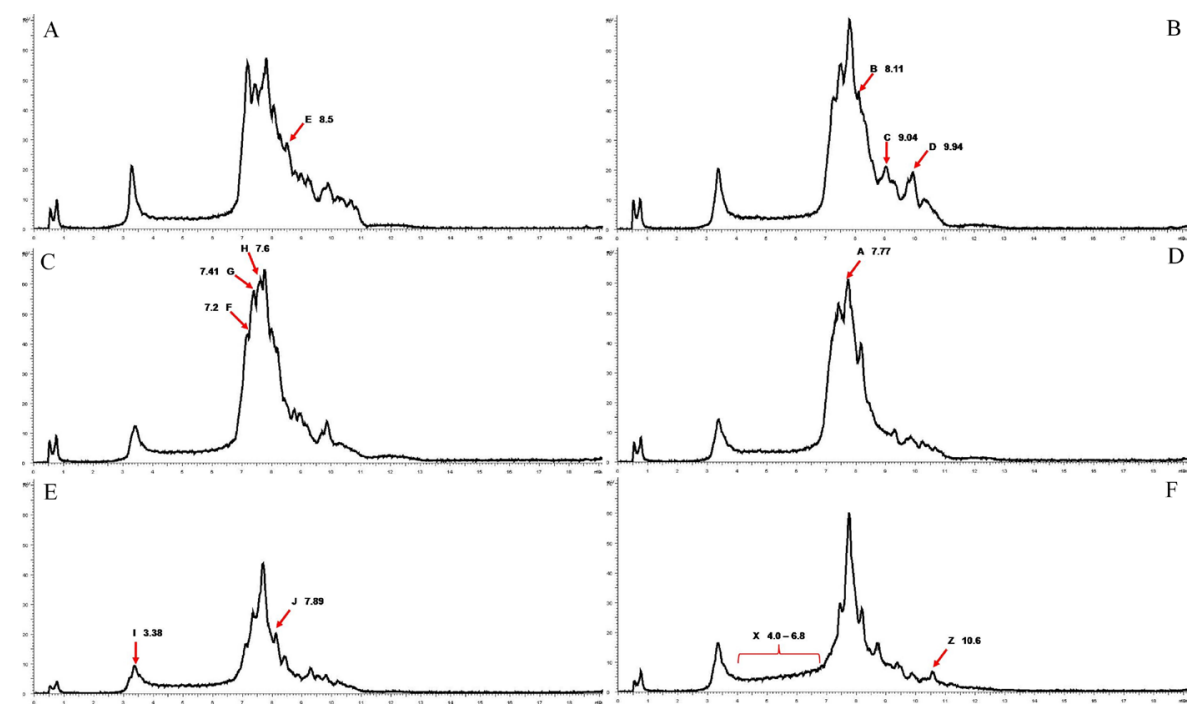

Figure 1. DHPLC of amplified 16S rDNA isolated from samples of cassava-fermented broth. Chromatograms represent the bacterial diversity at different times of collection. Arrows indicate the peaks that were chosen at random and named after the fermentation time (on a daily basis), as follows: (A) day 2, peak E; (B) day 3, peaks B, $\mathrm{C}$ and D; (C) day 4 (84 h), peaks F, G and H; (D) day 4 (96 h), peak A; (E) day 5, peaks I and J; (F) day 7, peaks X and $\mathrm{Z}$. Samples from days 1 and 6 were not included in this study.

The first approach (the one in which the GC-clamp was removed before cloning) produced 132 bacterial rDNA sequences with an average size of $200 \mathrm{bp}, 45 \%$ of which have some degree of similarity to $16 \mathrm{~S}$ rDNA sequences from the database that are identified as environmental bacteria, either uncultivable or non-classified. We also identified sequences belonging to the Proteobacteria (29\%), Firmicutes (22\%), Bacteroidetes (3\%), and Actinobacteria (1\%), as shown in Figure 2.

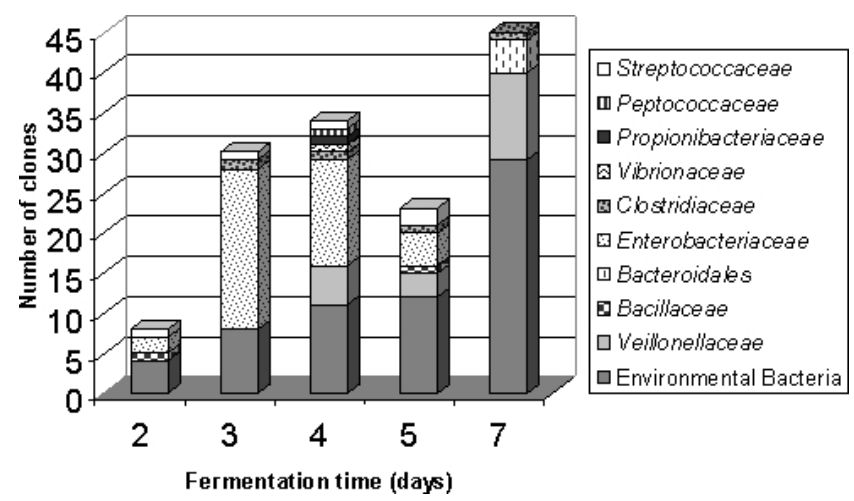

Figure 2. Taxonomic profile of bacteria from cassava-fermented broth as detected through PCR-DHPLC using an approach in which the GC-clamp was removed before cloning the $16 \mathrm{~S}$ rDNA fragments. 
The second approach produced 194 sequences that were identified as Proteobacteria (48\%), uncultured or non-classified environmental bacteria (40\%), and Firmicutes belonging to the Clostridia class (12\%), as shown in Figure 3.

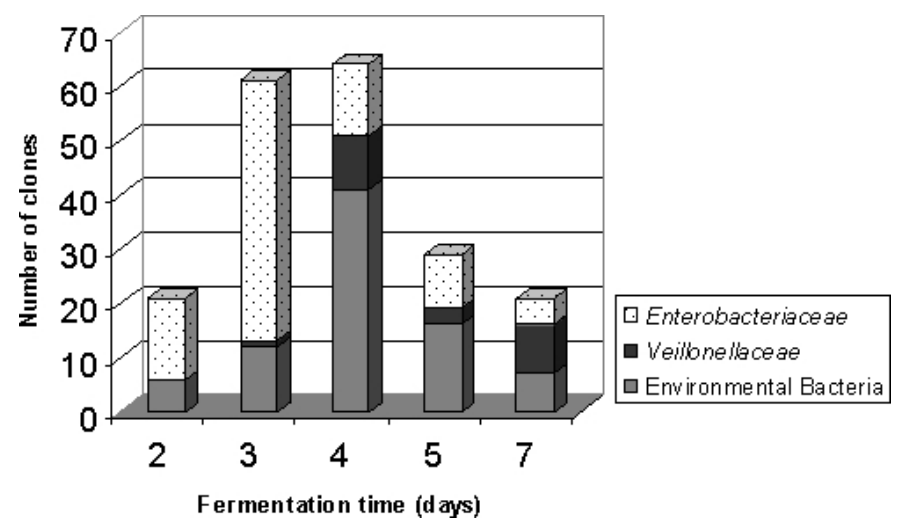

Figure 3. Taxonomic profile of bacteria from cassava-fermented broth as detected through PCR-DHPLC using an approach in which the GC-clamp was maintained in the $16 \mathrm{~S}$ rDNA clone libraries.

Because we used 2 approaches, we believe that it would be better to show the general diversity taking the 2 results together than showing the individual results. These results are shown in Figure 4.

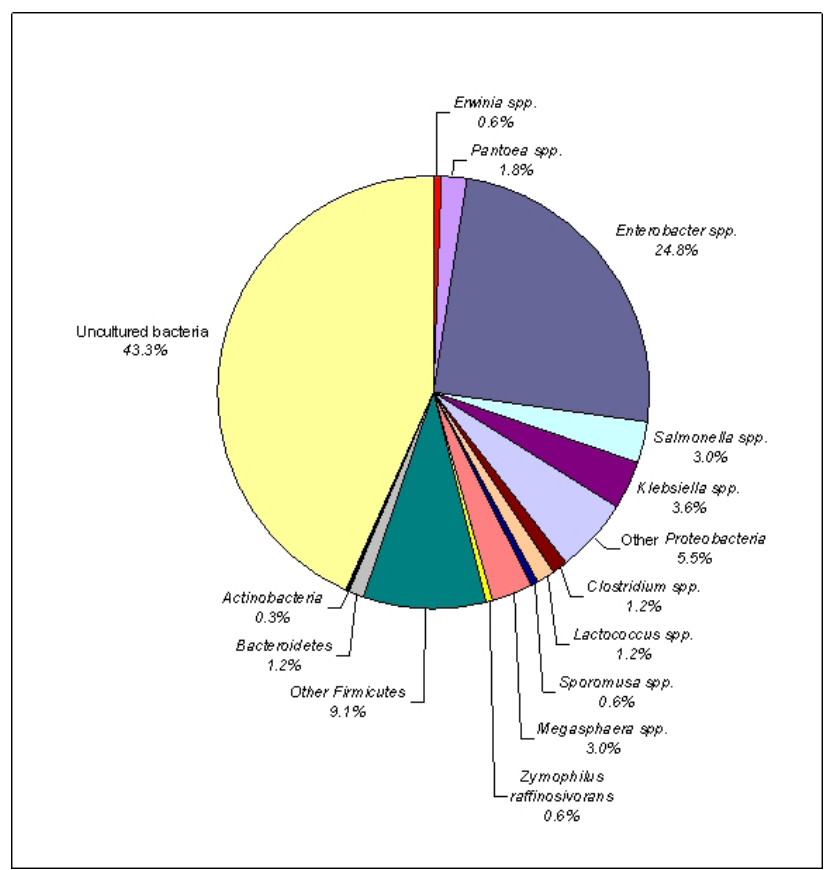

Figure 4. Diversity of endophytic bacteria from the cassava fermentation broth, as detected using PCR-DHPLC. The estimates of the two approaches are presented together. Bacteria were grouped at genus level. 


\section{DISCUSSION}

We describe a new approach for the identification of endophytic bacterial strains based on genetic variation. We used DHPLC to monitor the bacterial communities that were present for 7 days of cassava fermentation. We used PCR and cloning as accessory methods and the 16S rRNA gene as a genetic marker. We determined the best analytical conditions for DHPLC to allow the discrimination of the endophytic bacteria that were present in cassava fermentation broth. The best temperature for $16 \mathrm{~S} \mathrm{rDNA}$ fragment resolution was $64.5^{\circ} \mathrm{C}$ when the WAVE system was operated on the universal linear mode, which agrees with previously published data (Barlaan et al., 2005).

It has been postulated that the use of PCR-based molecular techniques for the study of microbial ecology has an inherent disadvantage of possibly generating bias that could affect the measure of taxonomic diversity, for instance, by selectively amplifying some sequences. Furthermore, the use of GC-clamped primers in PCR is considered a prime requirement for DHPLC analysis of amplified sequences, and this could possibly result in a further bias in the sequence analysis. In spite of this, no studies have yet been conducted to evaluate the influence of this clamp on the subsequent analysis of the DHPLC-separated fragments.

Here, we evaluated how the removal of the GC-clamp influenced cloning and diversity estimation. We observed important differences in the bacterial diversity at the genus and species levels when 2 distinct approaches were used, namely, when we removed the GC-clamp from the DHPLC-separated sequences before cloning and sequencing (first approach), and when we did not (second approach) (Figures 2 and 3). We demonstrated with this experiment that a second PCR to remove the GC-clamp before cloning results in a larger number of taxonomically different clones and contributes to an increase in the sensitivity of the method because a greater diversity was observed at the phylum and family levels (Figure 2) than in the approach where the GC-clamp was maintained (Figure 3).

According to our results, a high proportion of the $16 \mathrm{~S}$ rDNA that was isolated from the cassava-fermented broth corresponded to non-classified environmental bacteria. These unidentified sequences increase dramatically in frequency towards the end of the experiment (Figure 2); it is remarkable that these endophytic organisms remain unclassified because they possibly play a crucial role in cassava fermentation kinetics and on the overall fermented product quality.

Considering the 2 approaches, the phylum that was the most frequently detected during the cassava fermentation process was the Proteobacteria (39\%), mainly those representatives belonging to the Gamma and Alpha subdivisions. The most frequently identified family was the Enterobacteriaceae, which includes facultative anaerobic bacteria that are able to ferment sugars to produce acids or butanediol (Kersters et al., 2006). These bacteria were more frequently detected on the $2 \mathrm{nd}$ and 3rd days, suggesting an adaptation to the environmental $\mathrm{pH}$.

The greatest diversity of taxa was observed on the 4th day, when 4 distinct peaks were sampled at different fermentation times. A direct correlation between the number of peaks and the number of taxa detected was observed. Sequences that were assigned to the Clostridiales, mainly to the Family Veillonellaceae (formerly known as Acidaminococcaceae), were detected through both approaches from the 2 nd until the 7 th day.

Representatives of lactic bacteria were detected throughout the whole process, except on the 7th day, mainly when the first approach was used. The second most frequently detected phylum was Firmicutes (16\%), while Bacteroidetes and Actinobacteria were less represented using this method. 
The presence of representatives of the Firmicutes was significant, suggesting that they play an important role in the cassava fermentation process, as described previously (Meraz et al., 2006). The Firmicutes represented 22 and $12 \%$ of the total number of clones that we analyzed through the first and the second approaches, respectively.

Many species that were found using the first approach were also found using the second. For instance, the Veillonellaceae were represented from the 3rd day on, mainly by Megasphaera cerevisiae. However, when we used the second approach, only 2 known groups (Enterobacteriaceae and Veillonellaceae) and environmental non-classified bacteria could be detected. Our results not only show that the sensitivity for bacterial diversity determination was greater when we used the first approach but also show that the greatest relative bacterial diversity occurred on the 4 th and the 5th days (Figures 2 and 3 ). An overall view of the cassava fermentation broth bacterial diversity, as detected through DHPLC, is presented in Figure 4.

DHPLC was efficient in detecting a vast bacterial diversity that was associated with cassava fermentation. Additionally, it proved to be a non-laborious, fast, and efficient method; thus, it is a promising alternative for the identification and monitoring of microbial diversity in complex samples.

\section{ACKNOWLEDGMENTS}

Research supported by Fundação Amazônia Paraense (FAPESPA), Coordenação de Aperfeiçoamento de Pessoal de Nível Superior (CAPES), and Conselho Nacional de Desenvolvimento Científico e Tecnológico (CNPq).

\section{Supplementary material}

\section{REFERENCES}

Balota RL, Lopes ES, Hungria M and Döbereiner J (1999). Ocorrência de bactérias diazotróficas e fungos micorrízicos arbusculares na cultura da mandioca. Pesq. Agropec. Bras. 34: 1265-1276.

Barlaan EA, Sugimori M, Furukawa S and Takeuchi K (2005). Profiling and monitoring of microbial populations by denaturing high-performance liquid chromatography. J. Microbiol. Methods 61: 399-412.

Choi GW, Kang HW, Moon SK and Chung BW (2010). Continuous ethanol production from cassava through simultaneous saccharification and fermentation by self-flocculating yeast Saccharomyces cerevisiae CHFY0321. Appl. Biochem. Biotechnol. 160: 1517-1527.

Domann E, Hong G, Imirzalioglu C, Turschner S, et al. (2003). Culture-independent identification of pathogenic bacteria and polymicrobial infections in the genitourinary tract of renal transplant recipients. J. Clin. Microbiol. 41: 5500-5510.

Edgar RC and Batzoglou S (2006). Multiple sequence alignment. Curr. Opin. Struct. Biol. 16: 368-373.

Goldenberg O, Herrmann S, Marjoram G, Noyer-Weidner M, et al. (2007). Molecular monitoring of the intestinal flora by denaturing high performance liquid chromatography. J. Microbiol. Methods 68: 94-105.

Hall TA (1999). BioEdit: A user-friendly biological sequence alignment editor and analysis program for Windows 95/98/ NT. Nucleic Acids Symp. Ser. 41: 95-98.

Hung PQ, Kumar SM, Govindsamy V and Annapurna K (2007). Isolation and characterization of endophytic bacteria from wild and cultivated soybean varieties. Biol. Fertil. Soils 44: 155-162.

Hurtle W, Lindler L, Fan W, Shoemaker D, et al. (2003). Detection and identification of ciprofloxacin-resistant Yersinia pestis by denaturing high-performance liquid chromatography. J. Clin. Microbiol. 41: 3273-3283.

Hutzler M, Geiger E and Jacob F (2010). Use of PCR-DHPLC (polymerase chain reaction - denaturing high-performance liquid chromatography) for the rapid differentiation of industrial Saccharomyces pastorianus and Saccharomyces cerevisiae strains. J. Inst. Brew 116: 464-474.

Ibáñez F, Angelini J, Taurian T, Tonelli ML, et al. (2009). Endophytic occupation of peanut root nodules by opportunistic Gammaproteobacteria. Syst. Appl. Microbiol. 32: 49-55. 
Jacinto RC, Gomes BP, Desai M, Rajendram D, et al. (2007). Bacterial examination of endodontic infections by clonal analysis in concert with denaturing high-performance liquid chromatography. Oral Microbiol. Immunol. 22: 403410.

Kakela JK, Friedman KD, Haberichter SL, Buchholz NP, et al. (2006). Genetic mutations in von Willebrand disease identified by DHPLC and DNA sequence analysis. Mol. Genet. Metab. 87: 262-271.

Kersters K, De Vos P, Gillis M, Swings J, et al. (2006). The Prokaryotes. In: Introduction to the Proteobacteria. 3rd edn. (Dworkin M, Falkow S, Rosenberg E, Schleifer K-H, et al., eds.). Springer, New York, 3-37.

Li WF, Hu Z, Rao NY, Song CG, et al. (2008). The prevalence of BRCA1 and BRCA2 germline mutations in high-risk breast cancer patients of Chinese Han nationality: two recurrent mutations were identified. Breast Cancer Res. Treat. 110: 99-109.

Mattos KA, Padua VL, Romeiro A, Hallack LF, et al. (2008). Endophytic colonization of rice (Oryza sativa L.) by the diazotrophic bacterium Burkholderia kururiensis and its ability to enhance plant growth. An. Acad. Bras. Cienc. 80: 477-493.

Meraz M, Shirai K, Larralde P and Revah S (2006). Studies on the bacterial acidification process of cassava (Manihot esculenta). J. Sci. Food Agric. 60: 457-463.

Muyzer G, de Waal EC and Uitterlinden AG (1993). Profiling of complex microbial populations by denaturing gradient gel electrophoresis analysis of polymerase chain reaction-amplified genes coding for 16S rRNA. Appl. Environ. Microbiol. 59: 695-700.

Pruesse E, Quast C, Knittel K, Fuchs B, et al. (2007). SILVA: a comprehensive online resource for quality checked and aligned ribosomal RNA sequence data compatible with ARB. Nucleic Acids Res. 35: 7188-7196.

Rasche F, Lueders T, Schloter M, Schaefer S, et al. (2009). DNA-based stable isotope probing enables the identification of active bacterial endophytes in potatoes. New Phytol. 181: 802-807.

Rijavec T, Lapanje A, Dermastia M and Rupnik M (2007). Isolation of bacterial endophytes from germinated maize kernels. Can. J. Microbiol. 53: 802-808.

Teixeira MA, Melo IS, Vieira RF, Costa FEC, et al. (2007). Microrganismos endofíticos de mandioca de áreas comerciais e etnovariedades em três estados brasileiros. Pesq. Agropec. Bras. 42: 43-49.

Trujillo-López A, Camargo-Zendejas O, Salgado-Garciglia R, Cano-Camacho H, et al. (2006). Association of Gluconacetobacter diazotrophicus with roots of common bean (Phaseolus vulgaris) seedlings is promoted in vitro by UV light. Can. J. Bot. 84: 321-327.

Wagner AO, Malin C and Illmer P (2009). Application of denaturing high-performance liquid chromatography in microbial ecology: fermenter sludge, compost, and soil community profiling. Appl. Environ. Microbiol. 75: 956-964.

Wurzburger RJ, Gupta R, Parnassa AP, Jain S, et al. (2003). Use of GC clamps in DHPLC mutation scanning. Clin. Med. Res. 1: 111-118.

Zhang QH, Lu X, Tang L, Mao ZG, et al. (2010). A novel full recycling process through two-stage anaerobic treatment of distillery wastewater for bioethanol production from cassava. J. Hazard. Mater. 179: 635-641. 